\title{
KRISTDEMOKRATERNAS VÄLJARSTÖD EFTER GUDSTJÄNSTBESÖK 1988-2018
}

\author{
Magnus Hagevi, Institution för statsvetenskap, Linnéuniversitet \\ E-post I magnus.hagevi@1nu.se
}

\section{Inledning}

I en omfattande komparativ studie från slutet av 1960-talet konstaterade Richard Rose och Derek Urwin, till skillnad från allmänt vedertagna antaganden i tidigare forskning, att "[r]eligion, not class, is the main social base of parties in the Western world today." (Rose och Urwin 1969: 12). Därmed skulle religion tendera att vara den viktigaste sociala skiljelinjen i politiken, det vill säga det som identifierar olika samhällsgrupper med motstridiga politiska intressen (Lipset och Rokkan 1967). Utifrån teorier om grupp socialisation och kognition har framgått att individens religiositet kan relateras till politiska åsikter (Hagevi 2009). En sådan koppling kan röra såväl affektion som kognition. Speciellt religiöst engagerade människor kan använda religion för att orientera sig i politiken och leda dem till vilket parti de ska välja (Hagevi 2018).

Ungefär samtidigt som Rose konstaterade religionens betydelse för röstning i Västvärlden slutade det svenska valforskningsprogrammet att undersöka religionsröstning (Holmberg och Gilljam 1987: 17; jfr Särlvik 1970; Petersson 1977). När dessa undersökningar ett par decennier senare åter studerade den religiösa faktorn vid röstning konstaterade Mikael Gilljam att klass var den starkaste socioekonomiska förklaringen till röstning i Sverige, fast "[ä]nnu 1985 framstår dock den religiösa faktorn som en icke oviktig förklaring till varför svenska väljare röstar som de gör."

(C) 2018 Magnus Hagevi. Detta är en Open Access artikel distribuerad under CC-BY-NC som innebär att du tillåter andra att använda, sprida, göra om, modifiera och bygga vidare på ditt verk, men inte att verket används i

kommersiella sammanhang. http://dx.doi.org/10.15626/sj.20180503 
(Holmberg och Gilljam 1987: 210). I Sverige, precis som i andra europeiska länder, tenderade religiöst engagerade väljare att i större utsträckning rösta på borgerliga partier (Holmberg och Gilljam 1987), ett samband som senare studier bekräftat (Hagevi 2009). Gilljam noterade också att sambandet mellan religiöst engagemang och partival hade minskat från slutet av 1960-talet till mitten av 1980-talet (Holmberg och Gilljam 1987). Även senare studier visar att sambandet mellan väljarnas religiösa engagemang och partival minskat (Hagevi 2018). Religionens minskade politiska betydelse är i linje med dealignment - att den politiska betydelsen av socioekonomiska skiljelinjer minskar och att socioekonomiska faktorer som klass och religion förklarar allt mindre av väljarnas partival (Dalton $\mathrm{m}$ fl 1984). I den omfattande forskningen om väljar-dealignment visar de flesta resultat att de sociala skiljelinjer, som en gång varit betydelsefulla, har minskat i betydelse (Dalton 2013; Oscarsson och Holmberg 2013). Detta kan sättas i samband med sekularisering, det vill säga att religion betyder allt mindre för allt fler människor och inom allt fler samhällsområden (Hagevi 2009). En sådan förändring implicerar bland annat att religiösa väljare i allt mindre utsträckning röstat på partier som traditionellt företräder dem. Vid sidan av denna förändring har andelen religiöst engagerade väljare minskat (Hagevi 2018), vilket minskar religiösa väljares inflytande över valresultaten.

Det finns forskare som menar att dealignment utmed religiösa skiljelinjer är mindre omfattande (Inglehart 1977: 217-225). För det första antas att familjesocialisationen är starkare för religion än för andra sociala skiljelinjer: föräldrarna tros vara mer måna om att föra över värden och åsikter knutna till religion jämfört med till exempel klass. För det andra innebär sekularisering ett ifrågasättande av religiösa värden, vilket kan aktivera religiösa väljare politiskt och stärka sambandet mellan religiöst engagemang och partival. I svenskt sammanhang kan ett sådant exempel vara Kristdemokraternas nationella genombrott 1991 och att partiet sedan dess varit representerade i riksdagen. Partiets mobilisering av religiösa väljare kan vara en extra injektion för svensk religionsröstning (Demker 1998; Hagevi 2005). Kristdemokraterna bildades redan 1964 och hade redan före inträdet i Riksdagen en tämligen stor representation i vissa kommunoch landstingsfullmäktige - speciellt i Jönköpings län. Kristdemokraternas förändrade roll i svensk politik, sekularisering och dealignment mellan väljare och partier är processer som ägt rum på sikt och som därför bör belysas genom att jämföra förhållandet mellan religiositet och politik över tid. Detta gör det extra intressant att söka ett svar på frågan: Vilket samband finns mellan väljarnas gudstjänstbesök och stöd för Kristdemokraterna?

I det följande presenterar först studiens data, variabler och statistiska mått. Sedan beskrivs sambandet mellan gudstjänstbesök och Kristdemokraterna. Till sist presenteras studiens huvudslutsatser.

\section{Data och variabler}

Avsikten är att studera sambandet mellan gudstjänstbesök och stödet för Kristdemokraterna bland svenska väljare. För att kunna uttala sig om detta behövs data. Det finns givetvis många andra sätt att undersöka religiöst engagemang (Leege och Kellstedt 1993). Gudstjänstbesök är inriktat på beteende, medan det finns religiöst engagemang som är mer psykologiskt. Fördelen att analysera gudstjänstbesök är att detta kan knytas till teoretiska antaganden om socialisation där affektion 
respektive kognition är viktiga element. Gudstjänstbesök är en religionsutövning som till stor del är relaterad till kristendom. Enligt Surveyinstitutets undersökningar (se nedan) av personer som minst en gång i månaden besöker gudstjänst identifierar sig 88 procent som kristna, medan 5 procent identifierar som muslimer $(\mathrm{n}=104)$.

Studiens data är vetenskapliga frågeundersökningar av svenska väljare och svenska befolkningen. För att undersöka tre decenniers väljarbeteende är det två sorters sådana data som används: SVTvalu och SOM-institutets undersökningar. Båda analyseras utan viktningar i urvalet. För det första studeras väljarnas gudstjänstbesök och röstning genom SVT-valu 1991-2018. SVT-valu är en vallokalsundersökning som genomförs av Sveriges television i samarbete med Göteborgs universitet och Kungliga tekniska högskolan (Oscarsson m fl 2018). Enkäten behandlar bland annat hur svarspersonera röstat och hur ofta de besöker gudstjänst. Frågan om gudstjänstbesök lyder: "Hur ofta brukar Du gå till gudstjänst eller på möte i någon kyrka/religiöst samfund?" med svarsmöjligheterna "Minst en gång i månaden", "Några gånger om året", "Mera sällan" och "Aldrig". Svaren delas in i tre kategorier: aldrig ("Aldrig"), sällan ("Några gånger om året" och "Mera sällan") och regelbundet ("Minst en gång i månaden"). Ju oftare väljaren besöker gudstjänst, desto större antas individens religiösa engagemang vara. Om väljarna röstar på Kristdemokraterna undersöks med frågan "Vilket parti röstade på i dag i riksdagsvalet?" Genom att vid två tillfällen (1991 och 1998) använda frågan om hur väljaren röstade i föregående riksdagsval är det möjligt att förlänga tidserien till 1988 samt erhålla data om gudstjänstbesök och partival 1994 (då väljarnas gudstjänstbesök inte undersöktes i SVT-valu). Frågan om hur väljarna röstade i föregående riksdagsval lyder: Vilket parti röstade Du på i förra riksdagsvalet [1988 eller 1994]? Procentbasen beräknas på alla väljare som uppger att de röstade på ett parti i riksdagsvalet.

Beroende på när enkäten genomfördes varierar det totala antalet svarande. Vid valet 1991 besvarade drygt 2700 personer enkäten, i valen 1994-2002 var antalet svarande ungefär 70009000 personer och 2006-2018 var antalet svaranden ungefär 11000-13000 personer. Det varierande antalet svarande på enkäten är en av två centrala orsaker till att antalet svarande som besöker gudstjänst regelbundet, sällan och aldrig varierar mellan olika undersökningstillfällen. Den andra orsaken är sekularisering som främst innebär att antalet som kategoriserats som att de sällan besöker gudstjänst över tid minskar i antal och att personer som svarat att del aldrig besöker gudstjänst ökar i antal (Hagevi 2018). Utifrån 1991 års SVT-valu var antalet svarande för skattningarna 1988 och 1991 bland de som besöker gudstjänst regelbundet 179-188 personer, sällan 1359-1435 personer och bland aldrig 788-899 personer. I skattningarna av partival mellan 1994 och 2002 var antalet svarande bland de som besöker gudstjänst regelbundet 596-633 personer, sällan 4566-4864 personer och aldrig 2501-3198 personer. Mellan 2006-2018 var antalet svarande bland de som besöker gudstjänst regelbundet 719-854 personer, sällan 47195904 personer och aldrig 5008-5948 personer.

För det andra studeras gudstjänstbesök och partisympati genom de frågeundersökningar som genomförs av SOM-institutet vid Göteborgs universitet mellan 1988-2018 (SOM-institutet 2019). Dessa frågeundersökningar genomförts i form av postenkäter riktade till representativa urval av svenska befolkningen mellan 16-75/80/85 år (den övre åldersgränsen har succesivt höjts i undersökningarna). I SOM-undersökningar studeras gudstjänstbesök i ett frågebatteri som inleds 
med följande fråga: "Hur ofta har Du under de senaste 12 månaderna gjort följande saker?" Därefter nämns bland annat "Besökt gudstjänst eller religiöst möte". Svarsalternativen är "Ingen gång", "Någon gång under de senaste 12 månaderna", "Någon gång i halvåret", "Någon gång i kvartalet", "Någon gång i månaden", "Någon gång i veckan" samt "Flera gånger i veckan". Dessa uppgifter analyseras genom att dela in svaren i tre kategorier: aldrig ("Ingen gång"), sällan (från "Någon gång under de senaste 12 månaderna" till "Någon gång i kvartalet") och regelbundet (från "Någon gång i månaden" till "Flera gånger i veckan").

I SOM-undersökningarna registreras kristdemokratisk partisympati genom frågan "Vilket parti tycker Du bäst om idag?" Procentbasen beräknas på alla väljare som uppgav partisympati. Notera att SOM-institutet genomför sina undersökningar varje år, inte bara vid riksdagsval. Därför analyseras inte svarspersonernas röstning utan deras partisympatier, något som väljarna kan redovisa även när det inte är val.

Beroende på vilket år undersökningen genomförs har SOM-institutet riktat frågan om gudstjänstbesök till olika stora urval. Åren 1988-1997, 2002-2004, 2014-2016 och 2018 varierade antalet svarande mellan ungefär 1300 och 1700 personer och åren 1998-2001, 20052013 och 2017 varierade antalet svarande mellan ungefär 2750 och 3200 personer. Återigen är det varierande antalet svarande på SOM-undersökningar en av två centrala orsaker till att antalet svarande som besöker gudstjänst regelbundet, sällan och aldrig varierar mellan olika undersökningstillfällen. Också nu är den andra orsaken den sekularisering som främst innebär att antalet som kategoriserats som att de sällan besöker gudstjänst över tid minskar i antal och att personer som svarat att del aldrig besöker gudstjänst ökar i antal (Hagevi 2018). Under åren med ett mindre urval är antalet svarande bland de som besöker gudstjänst regelbundet 110-201 personer, sällan 338-712 personer och aldrig 573-1137 personer. Under åren med ett större urval är antalet svarande bland de som besöker gudstjänst regelbundet 197-321 personer, sällan 6721191 personer och aldrig 1641-2152 personer.

I SOM-institutets undersökningar kan det vara ett ganska litet antal svarande som uppger att de besöker gudstjänst regelbundet. Därför är den statistiska osäkerheten större i skattningar av denna grupps partisympatier. Något som ökar säkerheten i SOM-undersökningarnas skattningar av partisympatier bland regelbundna gudstjänstbesökare är möjligheten till jämförelse över tid. Det rör sig då om betydligt fler svarspersoner än ett enstaka år. I den mån som en skattning inte kraftigt avviker från de intilliggande åren ökar därför trovärdigheten i skattningen. Plötsliga förändringar ett år som inte upprepas återkommande år har istället lägre trovärdighet. Möjligheten att under valår jämföra partisympatierna bland regelbundna gudstjänstbesökare i SOM-undersökningarna med motsvarande kategori i SVT-valu - som har betydligt större antal svarande - kan också validera resultaten från SOM-undersökningarna.

För att ytterligare validera SOM-institutets data jämförs resultat från 2010-2018 med motsvarande data som samlats in av Surveyinstitutet vid Linnéuniversitetet (Hagevi 2020). Behovet av att validera data rör speciellt gruppen regelbundna gudstjänstbesökare då antalet svarspersoner i denna grupp är få. Surveyinstitutet genomför frågeundersökningar vartannat år $\mathrm{i}$ form av postenkäter riktade till representativa urval av svenska befolkningen mellan 16/18-85 år (den yngre åldersgränsen höjdes 2014). I Surveyinstitutets undersökningar studeras gudstjänstbesök i 
ett frågebatteri som inleds med följande fråga: "Hur ofta har du under de senaste 12 månaderna gjort följande?" varpå mellan 2010-2016 "Besökt religiöst möte (t ex gudstjänst eller bön)" och 2018 "Besökt gudstjänst" nämns. Svarsalternativen är "Ingen gång", "Någon gång de senaste 12 månaderna", "Någon gång i halvåret", "Någon gång i kvartalet", "Någon gång i månaden", "Någon gång i veckan", "Flera gånger i veckan" och "Varje dag". Dessa uppgifter analyseras genom att dela in svaren i tre kategorier: aldrig ("Ingen gång"), sällan (från "Någon gång under de senaste 12 månaderna" till "Någon gång i kvartalet") och regelbundet (från "Någon gång i månaden" till "Varje dag").

Surveyinstitutets undersöker kristdemokratisk partisympati genom frågan "Vilket parti tycker du bäst om idag?" Procentbasen beräknas på alla väljare som uppgav partisympati. Notera att Surveyinstitutet genomför sina undersökningar vartannat år, inte bara vid riksdagsval. Därför analyseras inte svarspersonernas röstning utan deras partisympatier, något som väljarna kan redovisa även när det inte är val.

I Surveyinstitutets undersökningar varierar antalet svarande mellan 1170 och 1490 personer. Under åren är antalet svarande bland de som besöker gudstjänst regelbundet 80-129 personer, sällan 407-515 personer och aldrig 655-846 personer.

\section{Stödet för Kristdemokraterna efter gudstjänstbesök}

I figur 1 beskrivs andelen väljare som röstat på Kristdemokraterna i riksdagsvalen efter gudstjänstbesök. I figur 2 rapporteras andelen i svenska befolkningen som uppger att de sympatiserar med Kristdemokraterna efter gudstjänstbesök. I båda figurerna redovisas uppgifterna åren 1988-2018. Partiets stöd bland regelbundna gudstjänstbesökare markeras med heldragen linje, bland de som besöker gudstjänst sällan markeras med streckad linje och de som aldrig besöker gudstjänst markeras med prickad linje.

Kristdemokraternas klart största stöd finns bland väljare som besöker gudstjänst regelbundet. Att stödet för Kristdemokraterna var svagare i väljarkåren före riksdagsinträdet 1991 är inte förvånande. Som tidigare forskning noterat var dock stödet för Kristdemokraterna före denna händelse också betydligt svagare bland regelbundna gudstjänstbesökare (Hagevi 2011). Kristdemokraternas politiska genombrott 1991 ägde rum bland väljargrupper som både hade stor och liten gudstjänstvana. Strax därefter minskade stödet för Kristdemokraternas drastiskt, speciellt bland regelbundna gudstjänstbesökare. Detta var tiden för debatten om svenskt EUmedlemskap och Kristdemokraternas partilinje var starkt EU-positiv, vilket en stor del av deras potentiella väljarkår inte var. Detta var en anledning till att partiet tappade stöd och med nöd (eller snarare med hjälp av taktikröster) klarade sig kvar i riksdagen 1994 (Hagevi 1996). I detta val fick Kristdemokraterna 4,01 procent av rösterna och klarade småpartispärren med darr på ribban. 
Figur 1: Röstning på Kristdemokraterna, efter gudstjänstbesök, 1988-2018 (procent).

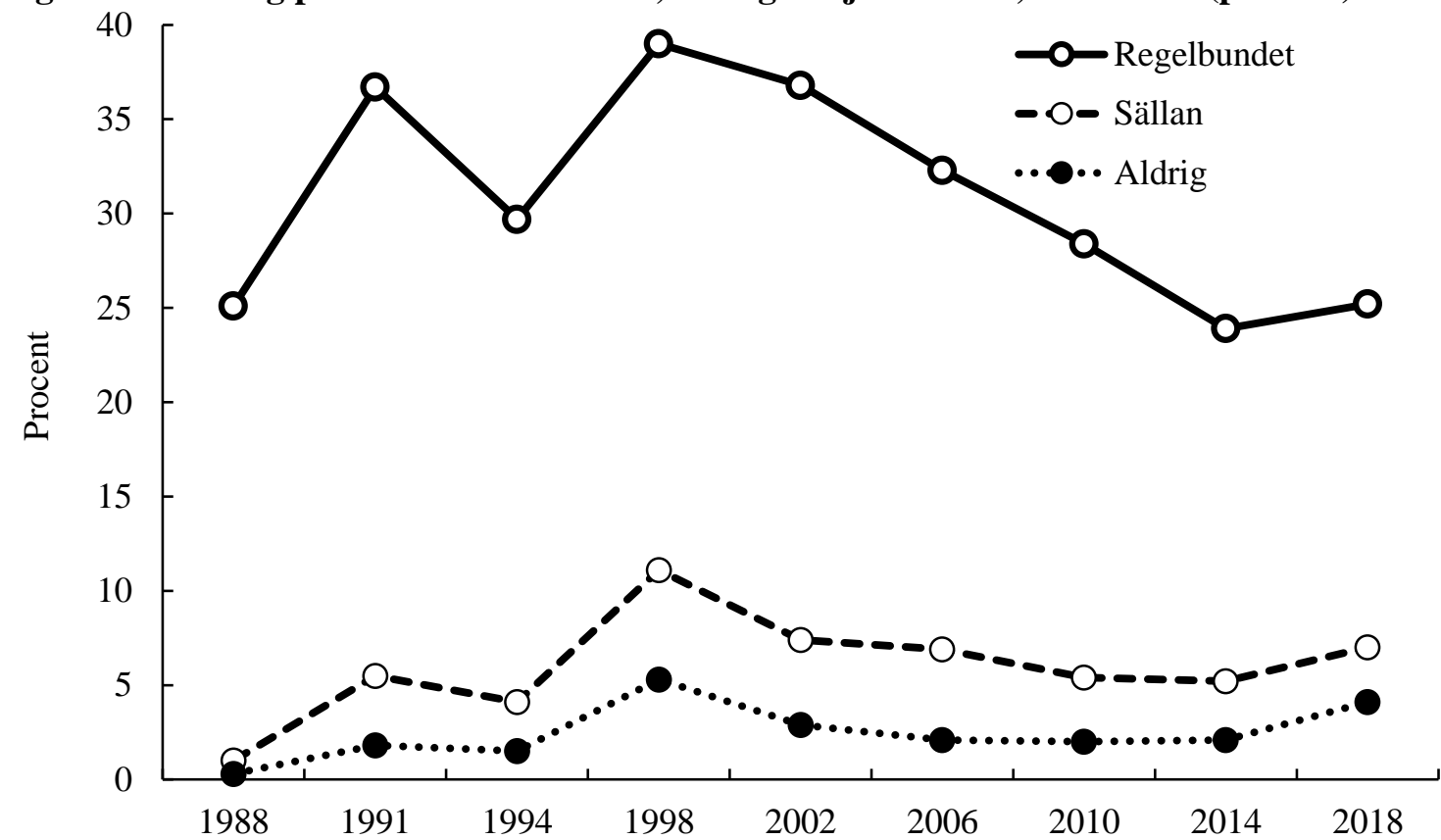

Kommentar: Data från SVT-valu. Frågan om röstning löd: "Vilket parti röstade på i dag i riksdagsvalet?", undantaget 1988 och 1994 då minnesuppgifter från 1991 respektive 1998 används: "Vilket parti röstade Du på i förra riksdagsvalet [1988/1994]?" Frågan om gudstjänstbesök löd: "Hur ofta brukar Du gå till gudstjänst eller på möte i någon kyrka/religiöst samfund?" Det var möjligt att svara "Minst en gång i månaden" (regelbundet), "Några gånger om året", "Mera sällan" (båda kategoriseras som sällan) och "Aldrig" (aldrig).

Figur 2: Partisympati för Kristdemokraterna, efter gudstjänstbesök, 1988-2018 (procent).

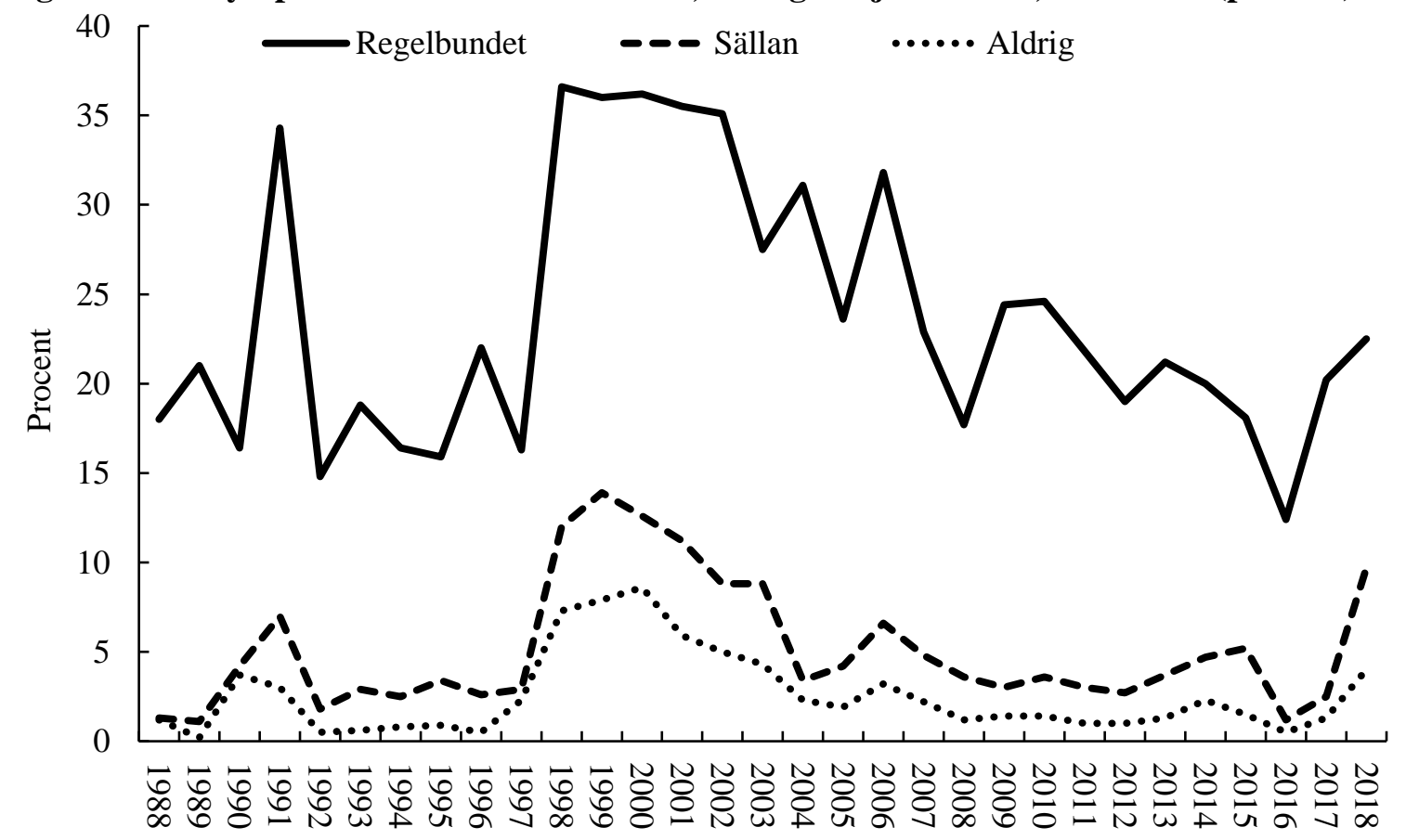


Kommentar: Data från SOM-institutet. Frågan om partisympati löd: "Vilket parti tycker Du bäst om idag?" Frågan om gudstjänstbesök löd: "Hur ofta har du under de senaste 12 månaderna gjort följande?", varpå bland annat "Besökt gudstjänst eller religiöst möte" nämndes. Det var möjligt att svara "Ingen gång" (kategoriserad som "aldrig"), " Någon gång under de senaste 12 månaderna", "Någon gång $i$ halvåret", "Någon gång i kvartalet" (dessa tre svar kategoriserade som "sällan"), "Någon gång i månaden", "Någon gång i veckan" och "Flera gånger i veckan" (dessa tre svar kategoriserade som "regelbundet").

Vid riksdagsvalet 1998 gick det betydligt bättre för Kristdemokraterna och de gjorde sitt hitintills bästa riksdagsval och fick 11,77 procent av rösterna. Det är också nu som Kristdemokraterna når rekordnivåer i alla tre aktivitetsnivåer av gudstjänstbesökare. Nästan 40 procent bland regelbundna gudstjänstbesökare, omkring dussinet procent bland väljare som sällan besöker gudstjänst och 5-7 procent bland väljarna som aldrig besöker gudstjänst. Åren mellan valen 19982002 kan beskrivas som de kristdemokratiska rekordåren, speciellt bland de regelbundna gudstjänstbesökarna. Där samlade partiet över 30 procent av väljarna.

Efter rekordåren tappar Kristdemokraterna väljare i varje riksdagsval fram till 2018. Enligt SOMinstitutet försvagas speciellt väljarstödet bland regelbundna gudstjänstbesökare efter riksdagsvalet 2006, medan partiet tappade en stor del av sitt stöd i mer sekulära väljargrupper redan före detta val. Forskning har påpekat att Kristdemokraterna tog steg bort från sina kristna kärnväljare efter riksdagsvalet 2006. Bland annat slutade partiledaren att uttryckligen referera till kristna värden (Brommesson 2010). Vid riksdagsvalet 2014 var stödet förhållandevis lågt i alla grupper med olika gudstjänstvanor; stödet bland regelbundna gudstjänstbesökare var i nivå med tiden för partiets inträde i riksdagen. Vid SOM-undersökningen 2016 noterade Kristdemokraterna ett bottenrekord då de samlade ett dussintals procent bland regelbundna gudstjänstbesökare.

I riksdagsvalet 2018 vände Kristdemokraternas stöd bland väljare med olika gudstjänstvanor. Bland de väljare som sällan eller aldrig besöker gudstjänst gjorde Kristdemokraterna sitt bästa val sedan rekordåren 1998-2002. Enligt SOM-institutet var dock partiets stöd bland regelbundna gudstjänstbesökare Kristdemokraternas fjärde sämsta under ett valår sedan 1988. Mellan 20062018 har Kristdemokraterna tappat en stor del av sitt stöd bland de som kan uppfattas som partiets kärnväljare: de regelbundna gudstjänstbesökarna. För att vara kristdemokrater, och i relation till tidigare valresultat, är däremot partiet ganska starka bland mer sekulära väljare 2018. Kristdemokraternas styrkebas är helt klart regelbundna gudstjänstbesökare, men det ter sig som om denna bas är svagare än förut och att partiet är långt ifrån rekordåren runt millennieskiftet.

Bland regelbundna gudstjänstbesökare är antalet svarande ibland relativt få i SOMundersökningarna. Till dessa skattningar finns därför en ökad osäkerhet jämfört med motsvarande kategori i SVT-valu. Men SVT-valu genomförs endast i samband med riksdagsvalen och kan därför inte validera SOM-undersökningarnas resultat som visar en plötslig och kraftig nedgång för Kristdemokraterna 2016 (följt av en uppgång som året efter återställer partiets nivå i opinionen). Sådana plötsliga förändringar ett år som korrigeras nästkommande år är speciellt osäkra med tanke på det fåtaliga antalet svarande bland regelbundna gudstjänstbesökare: är det ett mätfel eller något som inträffade i opinionen bland regelbundna gudstjänstbesökare? Turligt nog undersöker även Surveyinstitutet gudstjänstbesök och partisympatier vid tiden för Kristdemokraternas potentiella störtdykning i opinionen (2010-2018). Likt SOM- 
undersökningarna har även Surveyinstitutets undersökningar relativt få svarande som besöker gudstjänst regelbundet. Men om Surveyinstitutets undersökningar visar motsvarande resultat som noteras i SOM-undersökningarna - att de regelbundna gudstjänstbesökarnas stöd för Kristdemokraterna plötsligt minskar 2016 för att strax därefter återställas - stärks slutsatsen att denna förändring ägt rum. I figur 3 redovisas stödet för Kristdemokraterna efter gudstjänstbesök 2010-2018.

Figur 3: Partisympati för Kristdemokraterna, efter gudstjänstbesök, 1988-2018 (procent).

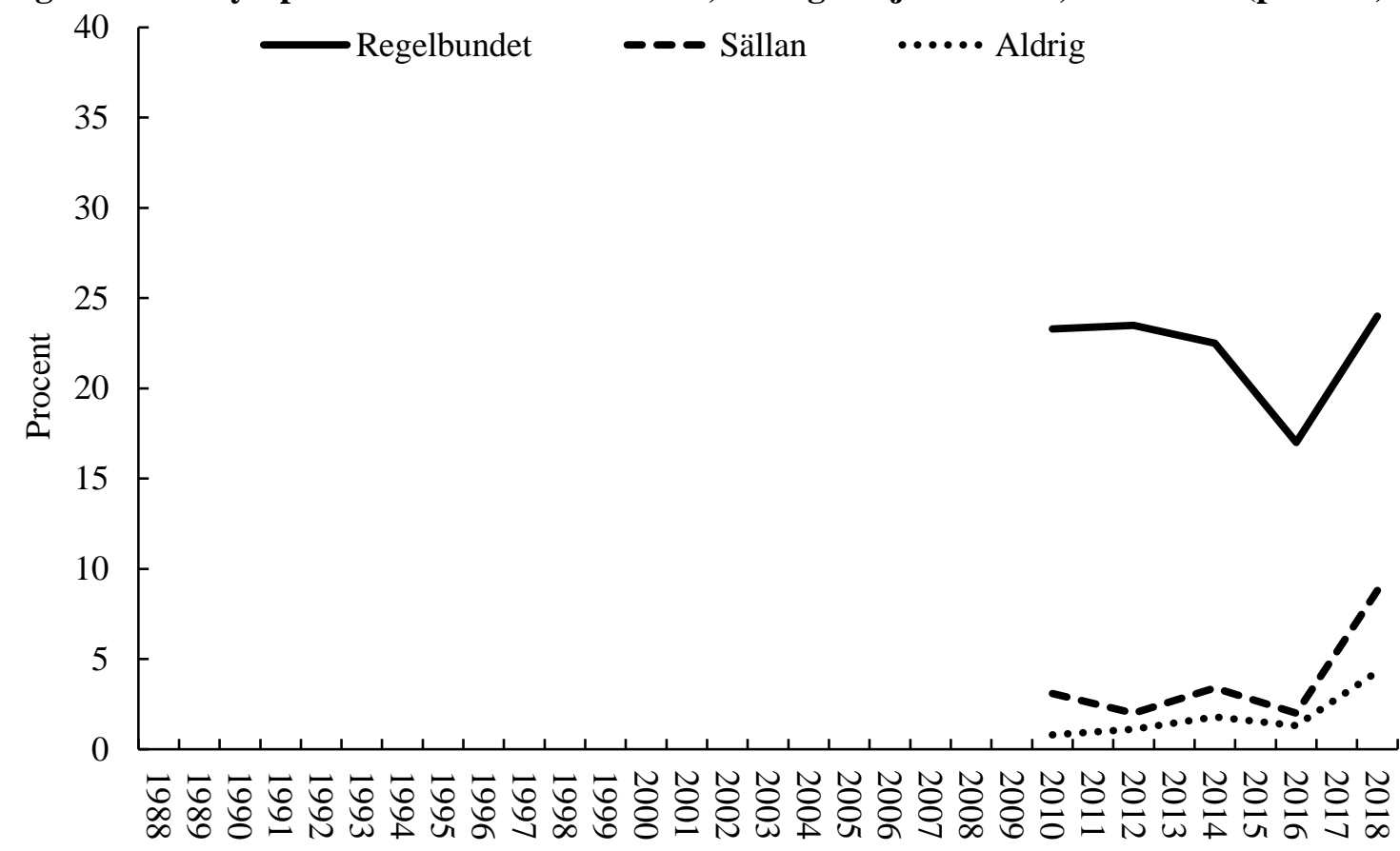

Kommentar: Data från Surveyinstitutet. Frågan om partisympati löd: "Vilket parti tycker Du bäst om idag?" Frågan om gudstjänstbesök löd: "Hur ofta har du under de senaste 12 månaderna gjort följande?", varpå bland annat "Besökt religiöst möte (gudstjänst eller bön)" alternativt " Besökt gudstjänst" nämndes. Det var möjligt att svara "Ingen gång" (kategoriserad som "aldrig"), " Någon gång under de senaste 12 månaderna", "Någon gång i halvåret", "Någon gång i kvartalet" (dessa tre svar kategoriserade som "sällan"), "Någon gång i månaden", "Någon gång i veckan", "Flera gånger i veckan" och "Varje dag" (dessa fyra svar kategoriserade som "regelbundet").

I allt väsentligt är det ungefär samma resultat i Surveyinstitutets undersökningar (om än något mindre drastisk förändring): Kristdemokraternas stöd bland regelbundna gudstjänstbesökare minskar 2016 för att åren därefter återställas till opinionsnivån åren före nedgången. Att det 2016 skedde en nedgång i kristdemokratiska partisympatier bland de regelbundna gudstjänstbesökarna får därmed stöd.

\section{Slutsatser}

Kristdemokraternas styrkebas är regelbundna gudstjänstbesökare. Partiets stöd är avsevärt starkare i denna väljargrupp än i mer sekulära väljargrupper. Ändå tycks stödet bland det som kan uppfattas vara Kristdemokraternas kärnväljare ha blivit svagare. Det gäller även vid riksdagsvalet 
2018 där valresultatet beskrevs som partiets återuppståndelse. Förvisso är Kristdemokraterna betydligt svagare bland väljare som sällan eller aldrig besöker gudstjänst, men sett över tid har partiet nått ett ganska bra resultat i dessa väljargrupper i riksdagsvalet 2018. Utifrån att den stora majoriteten väljare aldrig besöker gudstjänst är Kristdemokraternas väljarkår detta år bland de mest sekulära i partiets historia. Att skillnaden minskar mellan i vad mån regelbundna gudstjänstbesökare och mer sekulära väljargrupper röstar på Kristdemokraterna är en viktig anledning till att religionsröstningen avtar i svensk politik (Hagevi 2018). Mycket tyder också på att Kristdemokraterna inte kan räkna med att regelbundna gudstjänstbesökare i vått och torrt ska rösta på partiet. Inför valet 2018 pekar flera undersökningar på att partiet tappade stort i denna väljargrupp, ett förhållande som Kristdemokraterna redde upp inför riksdagsvalet 2018.

\section{Referenser}

Bjereld, Ulf och Douglas Brommesson (2007) Politik och kristen tro: Två berättelser. Stockholm: Santérus.

Brommesson, Douglas (2010) "Svenska kristdemokrater i förändring: Från konfessionellt universella till sekulärt partikulära." Statsvetenskaplig tidskrift, 112 (2): 165-175.

Brommesson, Douglas och Henrik Friberg-Fernros (2013) Bortom den sekulära staten: Religion och politik $i$ en postsekulär tid. Lund: Studentlitteratur.

Dalton, Russell J. (2013) Citizen Politics: Public Opinion and Political Parties in Advanced Industrial Democracies. Washington, DC: CQ Press.

Dalton, Russell J, Scott C Flanagan och Paul Allen Beck, red (1984) Electoral Change in Advanced Industrial Democracies: Realignment or Dealignment? Princeton: Princeton University Press.

Demker, Marie (1998) Religion och politik: Den europeiska kristdemokratins dilemma. Stockholm: SNS förlag.

Hagevi, Magnus (1996) "Religiositet och första valet till EU-parlamentet" s 89-107 i

Västsvenska perspektiv (SOM-rapport: 17), red Lennart Nilsson. Göteborg: SOM-institutet, Göteborgs universitet.

Hagevi, Magnus (2005) "Evangelikaler i svensk och amerikansk politik", s 134-162 i Religion och politik, red Magnus Hagevi. Malmö: Liber.

Hagevi, Magnus (2009) Politisk opinion och religiositet $i$ Västra Götaland. Lund: Sekel.

Hagevi, Magnus (2018) "Religionsröstning i Sverige 1988-2018." Surveyjournalen, 5 (1): 2-14.

Hagevi, Magnus (2020, kommande). ”Survey 2018: Teknisk rapport.” Surveyjournalen, 7 (1).

Holmberg, Sören och Mikael Gilljam (1987). Väljare och val i Sverige. Stockholm: Bonniers. 
Inglehart, Ronald (1977). The Silent Revolution: Changing Values and Political Styles Among Western Publics. Princeton: Princeton University Press.

Leege, David och Lyman Kellstedt, red (1993) Rediscovering the Religious Factor in American Politics. Armonk: M. E. Sharpe.

Lipset, Seymour M. och Stein Rokkan (1967) "Cleavage Structures, Party Systems, and Voter Alignments: An Introduction", s 1-64 i Party Systems and Voter Alignments, red Seymour Lipset och Stein Rokkan. New York: The Free Press.

Oscarsson, Henrik och Sören Holmberg (2013) Nya svenska väljare. Stockholm: Norstedts juridik.

Oscarsson, Henrik Ekengren, Per Näsman, Eva Landahl och Sören Holmberg (2018) VALU 2018 - SVT:s vallokalsundersökning riksdagsvalet 2018. Stockholm: Sveriges Television AB

Petersson, Olof (1977) Väljarna och valet 1976. Stockholm: Statistiska centralbyrån/Liber.

Rose, Richard och Derek Urwin (1969), "Social Cohesion, Political Parties and Strains in Regimes." Comparative Political Studies, 2 (1): 7-67.

SOM-institutet (2019) Super-Riks-SOM 1986-2018 (v2019.1). Göteborg: SOM-institutet, Göteborgs universitet.

Särlvik, Bo (1970) "Socioeconomic Position, Religious Behavior, and Voting in the Swedish Electorate: An Application of Computerized Classification Techniques." Quality and Quantity, 4 (1): 95-116. 